ISSN: 2581-8341

Volume 03 Issue 11 November 2020

DOI: 10.47191/ijcsrr/V3-i11-09, Impact Factor: 6.595

IJCSRR@ 2020

Www.ijcsrr.org

\title{
Implementation, Monitoring and Evaluation of a Novel In-Service Training Strategy of Public Health Staff: Evidence from Colombo Regional Directorate of Health Services, Sri Lanka
}

\author{
S.M. Arnold \\ Ministry of Health, Colombo 10, Sri Lanka
}

\begin{abstract}
Introduction: Continuous in-service training sessions help in updating and upgrading the competency of the public health field staff. Implementation of these sessions with the uniform delivery of the quality assured content has been a challenge in the Sri Lankan well-established preventive healthcare system.

Aim: To describe the implementation, monitoring and evaluation of a novel in-service training strategy of public health staff including Pubic Health Inspectors (PHI) and Public Health Midwives (PHM) conducted in the Colombo Regional Directorate of Health, Sri Lanka from January to June 2018.

Methods: A consultative meeting and a workshop was conducted with the participation of all stakeholders in reviewing the existing in-service training methodology and in recommending the strategies of overcoming the limitations of it. A novel strategy was developed for the implementation of in-service sessions with multi-level implementation and evaluation components. The in-service training sessions were conducted to improve the knowledge and quality of service provision by Public Health Inspectors, Public Health Midwives and other public health staff. Four evaluation indicators were defined. Descriptive statistics and the Wilcoxon signed rank test were used in the evaluation.

Results: By the consultative meetings and workshops, four main weaknesses of the existing in-service training system were revealed, and three characteristics of an ideal system were defined. Two process indicators have shown a coverage of the intervention of $100 \%$ while the median satisfaction scores were observed to be $85 \%$ or above. Two output/outcome indicators have shown that the interventions have yielded significantly higher post-intervention scores compared to the pre-intervention scores as perceived by the staff members $(\mathrm{p}<0.05)$, while the reception of feedback reports was $100 \%$.

Conclusions and Recommendations: The novel strategy is seemingly effective in relation to the four evaluation indicators used. Possibility of implementing similar strategies in other areas must be explored with the view of disseminating quality assured content with uniformity among the public health field staff categories in the monthly in-service sessions.
\end{abstract}

KEYWORDS: Public health staff; in-service training; Medical Officer of Health areas; Public Health Midwives; Public Health Inspectors

\section{INTRODUCTION}

A well-functioning preventive health sector is a crucial decisive factor in maintaining the standards and the achievements of a health system. Field health staff comprise of an important component in the delivery these preventive health services. Different health systems utilize different mechanism in the delivery and the appraisal of these field public health services(1). Sri Lanka is an example of a country with a well-established field health infrastructure in relation to the preventive public health services. The Sri Lankan model is proven to be with cost-effectiveness, in comparison to the peers of the same economic contexts(2).

Sri Lanka is divided into health units named as "Medical Officer of Health (MOH) areas". These MOH areas are well demarcated with geographical boundaries considering the population numbers as well. An ideal MOH setting is regarded to be catering a population of 60, 000 people. The staff members of the $\mathrm{MOH}$ officers include medical officers as well as other staff categories. The medical officer called as the "Medical Officer of Health" is the head of the institution and there are other supervisory staff categories as well. Under the guidance of the supervisory officers, the Public Health Midwives (PHMs) and Public Health Inspectors are delivering pre-defined duties. PHMs are mainly involved in the delivery of the maternal and child health services while the PHIs are involved in disease control, environmental health and occupation health services(3, 4). Most of the MOH areas of the country are immediately under the administration of the district level health directorate termed as the "Regional Health Directorate" (5). 


\section{International Journal of Current Science Research and Review}

ISSN: 2581-8341

Volume 03 Issue 11 November 2020

DOI: 10.47191/ijcsrr/V3-i11-09, Impact Factor: 6.595

IJCSRR@ 2020

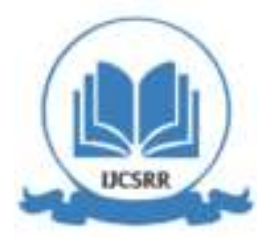

www.ijcsrr.org

Continuous upgrading of the technical knowledge and skills of the public health field staff is of utmost importance. The generic method of doing so is by conducting a in-service day for the staff mmebrs of MOH office in each month. Higher level programs are conducted occasionally as those cannot cover all of staff members them due to their higher numbers. Once those are done, two methods are currently in practice in. One is to conduct "training of trainers (ToT)" workshops and then to disseminate the technical components through these trained staff to lower levels $(6,7)$. Usually the supervisory staff members of each MOH area participate as the attendees in these. Secondly to conduct training sessions for selected number of staff from each $\mathrm{MOH}$ area and then to disseminate the content to others. However, there are debates over the effectiveness of both of these strategies. Similarly when the training opportunities are not equally distributed, the job satisfaction of the public health staff would become potentially reduced. Hence, ensuring a quality in-service training strategy with uniform dissemination of the content has been a challenge faced by each district level health directorate.

This paper discusses the aspects related to implementation, monitoring and evaluation of a novel in-service training strategy of public health staff conducted in the Colombo Regional Directorate of Health, Sri Lanka from January to June 2018.

\section{METHODS}

A consultative meeting and a workshop were conducted with the representation of all stakeholders. The consultative meeting was held on 03.12.2017 at the Western Provincial Directorate with the participation of: supervisory staff at the district level, supervisory staff of the $\mathrm{MOH}$ level, post-graduate trainees in Community Medicine(8). The strengths and weaknesses of the current in-service training strategies were discussed. Characteristics of an effective novel strategy in addressing these weaknesses were discussed.

Based on the suggestions, the district level supervisory staff developed a strategy in implementing the in-service sessions uniformly within the MOH areas of the district. The workshop was held on 21.12.2017 at Boralasgamuwa MOH Office(8). The objective was to review the developed plan and to decide on a schedule of topics to be discussed in each month. From each MOH areas, two medical doctors and other supervisory officers participated in this workshop.

Since the plan was approved by all the participants topics and the timeline were discussed. It was planned to have this novel strategy in place for six months (i.e. from January to June 2018). Two indicators were for the process-evaluation and two for the and output/outcome-evaluation as shown in Figure 1.

\begin{tabular}{|l|l|}
\hline Process-evaluation $(\mathbf{9}, \mathbf{1 0})$ & Output/outcome-evaluation(9, 10) \\
\hline $\begin{array}{l}\text { Indicator 1: } \\
\text { The number of training days conducted according to the novel } \\
\text { strategy (out of 6) }\end{array}$ & $\begin{array}{l}\text { Indicator } 1: \\
\text { The self-perceived pre- and post-awareness of the staff } \\
\text { members }\end{array}$ \\
\hline $\begin{array}{l}\text { Indicator 2: } \\
\text { The feedback of staff given over the satisfaction of novel strategy } \\
\text { (from a scale of 1-100) for two domains; content, quality of materials } \\
\text { and on methodology in general }\end{array}$ & $\begin{array}{l}\text { Indicator 2: } \\
\text { The number of feedback reports received from each } \\
\mathrm{MOH} \text { area (out of 6 per MOH area) }\end{array}$ \\
\hline
\end{tabular}

\section{Figure 1: Evaluation indicators}

Wilcoxon signed rank test was used in expressing the first output/outcome-indicator. The other indicators were shown with descriptive methods (i.e. percentages and median scores).

\section{RESULTS}

Figure 2 summarizes the key weaknesses of the existing system highlighted in the first consultative meeting.

- The content of the training sessions were not uniform across the district

- Mostly conventional teaching methods had been used

- When some sessions were mainly focusing on one staff category, other categories believed those as irrelevant for them

- A proper feedback system was not in use

Figure 2: The weakness highlighted in the existing in-service training at that time 


\section{International Journal of Current Science Research and Review}

ISSN: 2581-8341

Volume 03 Issue 11 November 2020

DOI: 10.47191/ijcsrr/V3-i11-09, Impact Factor: 6.595

IJCSRR@ 2020

www.ijcsrr.org

Figure 3 shows the characteristics of a novel strategy proposed at the end of the first consultative meeting.

- A systematically generated topics must be covered while keeping room for the area-specific sessions

- Teaching methods must include novel strategies like audio-visual materials

- A centrally coordinated monitoring system must be there

Figure 3: The proposed characteristics of a new strategy

The proposed model developed by the district level staff was as follows: Monthly in-service trainings would consist of two sessions; morning and afternoon. The morning session will be targeting all the staff members in the afternoon, the staff categories will be divided into two groups; the public health midwives' group and the public health inspectors' group. The afternoon sessions will be done at two locations of the MOH office. The content including the audio-visuals for each month would be prepared by the district level staff. This generic content would cover two third of the time of the day while the other one third could be allocated by each $\mathrm{MOH}$ office to cover specific requirements. Preparatory sessions would be done in the last week of each month for the following month's training day at a designated location. Two MOHs and other supervisory officers from each MOH office would participate in these preparatory sessions. The materials of each $\mathrm{MOH}$ area will be distributed at the preparatory session. This would include the videos, power point presentations, self-recording templates to be given to each participant and the feedback forms. The completed feedback forms and a short report (according to a structured format) will be sent to the RDHS office by each MOH office following the training day. Thus, the strategy included an in-built monitoring and evaluation component.

As decided, the strategy was implemented in the six months of 2018. Table 1 shows the feedback given by the staff members in relation to the; average self-perceived awareness on technical aspects before and after the in-service sessions. Both categories showed a statistically significant higher post-intervention awareness $(\mathrm{P}<0.05)$.

Table 1: Overall self-perceived awareness on technical aspects of the PHMs and PHIs

\begin{tabular}{|c|c|c|c|}
\hline Category & Pre-awareness Median & Post-awareness Median & Significance of the difference \\
\hline PHMs & 68 & 92 & $<0.05$ \\
\hline PHIs & 64 & 89 & $<0.05$ \\
\hline
\end{tabular}

Table 2 shows the satisfaction scores on the content covered, materials used and over the general methodology of the novel strategy.

Table 2: Satisfaction scores on the content covered, materials used and over the general methodology of the novel strategy

\begin{tabular}{|c|c|}
\hline Domain & Median \\
\hline Content covered & 92 \\
\hline Quality of materials & 89 \\
\hline Methodology in general & 85 \\
\hline
\end{tabular}

The proportion of training days conducted in each $\mathrm{MOH}$ areas was $100 \%$. Similarly, the proportion of reports received from each MOH area was $100 \%$.

Table 3 shows the pre versus post self-perceived level of awareness in relation to the 10 domains that were covered within these six months. Out of these, the domains 1,2,3,4,6,7,8 were targeting both the PHM and PHI categories. The domain 5 an 9 were specific for the PHMs and 10 was specific for the PHIs. In all domains, significant improvements were observed in the post-intervention awareness compared to the pre-awareness scores $(\mathrm{p}<0.05)$.

Table 3: Self-perceived awareness on technical aspects of the staff on the domains covered

\begin{tabular}{|l|l|c|c|c|}
\hline S.N. & Subject area & $\begin{array}{c}\text { Pre-awareness } \\
\text { Median }\end{array}$ & $\begin{array}{c}\text { Post-awareness } \\
\text { Median }\end{array}$ & $\begin{array}{c}\text { Significance of } \\
\text { the difference }\end{array}$ \\
\hline 1. & Health indicators & 63 & 87 & $<0.05$ \\
\hline 2. & $\begin{array}{l}\text { Non-Communicable Disease, Well-women services, } \\
\text { Healthy lifestyle clinics }\end{array}$ & 68 & 92 & $<0.05$ \\
\hline
\end{tabular}




\section{International Journal of Current Science Research and Review}

ISSN: 2581-8341

Volume 03 Issue 11 November 2020

DOI: 10.47191/ijcsrr/V3-i11-09, Impact Factor: 6.595

IJCSRR@ 2020

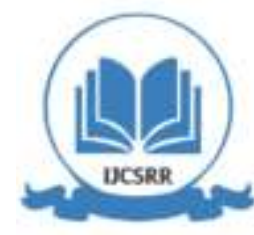

www.ijcsrr.org

\begin{tabular}{|l|l|c|c|c|}
\hline 3. & Family planning & 69 & 93 & $<0.05$ \\
\hline 4. & Adolescent health services, Life skills & 71 & 94 & $<0.05$ \\
\hline 5. & Micronutrients, Nutrition education & 67 & 93 & $<0.05$ \\
\hline 6. & $\begin{array}{l}\text { Primary Healthcare Services, Service provision by MOH } \\
\text { office, Office maintenance }\end{array}$ & 64 & 95 & $<0.05$ \\
\hline 7. & Quality of service, Conduction of local conference & 63 & 91 & $<0.05$ \\
\hline 8. & Vaccination services, Child development & 71 & 93 & $<0.05$ \\
\hline 9. & $\begin{array}{l}\text { Edinburgh post-natal depression scale, Gender-based } \\
\text { violence }\end{array}$ & 70 & 92 & $<0.05$ \\
\hline 10. & $\begin{array}{l}\text { Communicable disease surveillance, Waste management, } \\
\text { Disaster preparedness, School health service }\end{array}$ & 64 & 86 & $<0.05$ \\
\hline
\end{tabular}

\section{DISCUSSION}

This is the first formal evaluation of an in-service training intervention of public health staff done within a whole regional directorate in Sri Lanka. The findings suggest that the favourable outcomes have been achieved in relation to all the four indicators. . Two process indicators have shown a coverage of the intervention of $100 \%$ while the median satisfaction scores were observed to be $85 \%$ or above. Two output/outcome indicators have shown that the interventions have yielded significantly higher post-intervention scores compared to the pre-intervention scores as perceived by the staff members, while the reception of feedback reports was $100 \%$. The process and output/outcome evaluation indicators of the strategy were carefully selected $(9,10)$. The first process indicator was related to the coverage of the training sessions. With the complementary supervisions and the feedback mechanism, this indicator was found to be $100 \%$ meaning that the all sessions were conducted in all the MOH areas on the allocated six days within those six months. This is an excellent achievement as the expected health messages would have been uniformly distributed throughout the $\mathrm{MOH}$ areas. The provision of audio-visuals would have contributed in achieving this uniformity as well. The variations of the capacities of the trainers is regarded as a crucial factor in deciding the effectiveness of the previously done training strategies. The current strategy could overcome that limitation.

The second output/outcome-indicator was the satisfaction scores assigned by the staff members. For all the three selected components in measuring this, the median score was 85 or above. Multiple factors would have contributed in getting these higher satisfaction scores. Firstly, all the staff members got the opportunity to participate in training sessions coordinated by a higher-level, unlike in the routine strategies where selected staff members participate in such training opportunities. Secondly unlike the conventional techniques, more advanced and effective methods were used in developing these materials. Pretesting of the materials beforehand, helped in ensuring their quality.

The first output-indicator was the self-perceived difference between the pre- and post-training scores. As shown in Table 1 and 3 , the overall awareness as well as the domain-specific awareness of the staff members showed to be significantly improved following the training sessions compared to the baseline scores. Maintaining and improving the competency of the health staff is a must in ensuring the quality of health service delivery, which is seemingly well-achieved by this novel training strategy. The second outputindicator on the feedback reports received was found to be $100 \%$. This is also a great achievement as the feedback reports enable the evaluation of the intervention and also imposes a sense of accountability in those who conduct the training. This findings would be useful in defining prospective training strategies for the public health system which is subjected to continuous reforms(11).

There were several limitations of this strategy and the evaluation procedures. The awareness scores only included self-perceptions and not any objective assessment. However self-perceptions are also regarded as an important component of the evaluations even though an inclusive objective-component would have raised the quality of this process(12). Secondly the satisfaction and the awareness were not correlated with the associated factors like the age and working experience of the staff members. Even though it would have been nicer to explore these associations for descriptive purposes, the utilization of a paired analysis would have mitigated the influence of these factors on the improvement of the awareness. 


\section{International Journal of Current Science Research and Review}

ISSN: 2581-8341

Volume 03 Issue 11 November 2020

DOI: 10.47191/ijcsrr/V3-i11-09, Impact Factor: 6.595

IJCSRR@ 2020

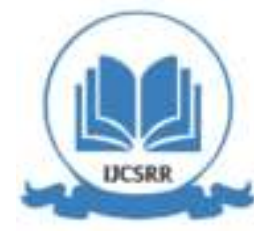

WWw.ijcsrr.org

\section{CONCLUSIONS}

The novel strategy implemented by the Regional Health Directorate of Colombo for the field public health staff, is seemingly effective in relation to the four evaluation indicators used. Possibility of implementing similar strategies in other areas must be explored with the view of disseminating quality assured content with uniformity among the public health field staff categories in the monthly in-service sessions.

\section{REFERENCES}

1. Gunathunga W, Fernando DN. Assessment of community maternal care performance of public health midwives of a province in Sri Lanka: a multi-method approach. Southeast Asian J Trop Med Public Health. 2000;31(2):310-8.

2. 2Senanayake S, Senanayake B, Ranasinghe T, Hewageegana NSR. How to strengthen primary health care services in Sri Lanka to meet the future challenges. Journal of the College of Community Physicians of Sri Lanka. 2017;23(1):43-9.

3. Perera D, Lund R, Swahnberg K, Schei B, Infanti JJ, team As. 'When helpers hurt': women's and midwives' stories of obstetric violence in state health institutions, Colombo district, Sri Lanka. BMC Pregnancy Childbirth. 2018;18(1):211.

4. Suriyakumar Mahendra Arnold, Sepali Wickrematilake, Dinusha Fernando, Roshan Sampath, Palitha Karunapema, Pasyodun Koralage Buddhika Mahesh. Distance education in improving knowledge, attitudes and skills of public health inspectors. TAPS 2020;5(2):32-40.

5. Mahesh PKB, Gunathunga MW, Arnold SM, De Silva LSD, Wijeratne MP, Weragoda J. Will prevention be better than cure? The challenge of retaining health staff in the public health sector in Sri Lanka. Journal of the College of Community Physicians of Sri Lanka. 2018;24(1).

6. Pearce J, Mann MK, Jones C, van Buschbach S, Olff M, Bisson JI. The most effective way of delivering a train-the-trainers program: a systematic review. J Contin Educ Health Prof. 2012;32(3):215-26.

7. Yarber L, Brownson CA, Jacob RR, Baker EA, Jones E, Baumann C, et al. Evaluating a train-the-trainer approach for improving capacity for evidence-based decision making in public health. BMC Health Serv Res. 2015;15:547.

8. Office of Provincial Director of Health Services- Western Province. MOH office-Colombo District ND [Available from: http://healthdept.wp.gov.lk/web/?page_id=1417.

9. National Center for HIV/AIDS-Viral Hepatitis-STD and TB Prevention. Types of evaluation. ND.

10. World Health Organization. How to evaluate the programme. ND. Contract No.: 4.

11. Perera S. Chapter 10-Primary Health Care Reforms in Sri Lanka: Aiming at Preserving Universal Access to Health. In: Medcalf A BS, Momen H, et al., editors., editor. Health For All: The Journey of Universal Health Coverage Hyderabad (IN): Orient Blackswan.

12. Jayatilleke AC, Yoshikawa K, Yasuoka J, Poudel KC, Fernando N, Jayatilleke AU, et al. Training Sri Lankan public health midwives on intimate partner violence: a pre- and post-intervention study. BMC Public Health. 2015;15:331.

Cite this Article: S.M. Arnold (2020). Implementation, Monitoring and Evaluation of a Novel In-Service Training Strategy of Public Health Staff: Evidence from Colombo Regional Directorate of Health Services, Sri Lanka. International Journal of Current Science Research and Review, 3(11), 194-198 